\title{
GRUPOTERAPIA BREVE DE MÚLTIPLOS CASAIS EM HOSPITAL-DIA ${ }^{1}$
}

\author{
Lenise Freitas Motta \\ FFCLRP - Universidade de São Paulo \\ Manoel Antônio dos Santos \\ FFCLRP - Universidade de Säo Paulo
}

\begin{abstract}
RESUMO: A Psicoterapia de Grupo com Casais (PGC) como modalidade específica de tratamento em um Hospital-dia (HD) público ligado à Universidade foi implantada em 1997, com o objetivo de destacar o casal como pólo de intervenção no tratamento, e apoiá-lo na situação de crise, com um dos cônjuges em regime de semi-internação na instituição. Este trabalho tem o objetivo descrever esta modalidade de tratamento, a partir da observação de onze sessões psicoterápicas consecutivas, gravadas em vídeo e transcritas na íntegra, com dados analisados segundo a modalidade de conteúdo categorial temático. Trata-se de um grupo com intensa participação dos terapeutas, que estimulam os casais e atuam através do fornecimento de informações, tendendo os participantes a serem mais passivos no processo, trazendo temas relativos ao cotidiano familiar, suas dificuldades em lidar com a patologia do cônjuge. Conclui-se que o grupo permite apoio para elaborar questões próprias da relação entre cônjuges em crise.
\end{abstract}

Palavras-chave: hospital-dia, psicoterapia de casais, grupoterapia

\section{BRIEF GROUPTHERAPY OF MULTIPLE COUPLES IN DAY HOSPITAL}

ABSTRACT: The Group Psychotherapy with Couples (GPC) as a specific modality of treatment in a public Day Hospital of the University was implanted in 1997, with the objective of placing the couple as treatment intervention pole, and support it in a crisis situation, with one of the partners in partial admission at the institution. The present study aims to describe this modality of treatment, through the observation of eleven consecutive psychotherapy sessions, recorded in video and later transcribed. The data were analyzed according to thematic categorical content analysis. It was observed that it is a support group, with intense participation of the therapists, who actively stimulated the couples and act providing information, and with the participants in one more passive role, bringing themes related to the familiar quotidian and difficulties in leading with the partner pathology. It is concluded that the group allows specific support to elaborate the relationship among partners in crisis.

Key words: Day Hospital, Psychotherapy for couples, Grouptherapy

\section{$O$ contexto no qual se insere o estudo}

O Hospital-Dia (HD), contexto onde o presente estudo se insere, é uma das modalidades assistenciais intermediárias entre a hospitalização integral e o tratamento ambulatorial. Oferece aos

\footnotetext{
${ }^{2}$ Psicóloga, mestre em Psicologia pelo Programa de Pós-graduação em Psicologia da Faculdade de Filosofia, Ciências e Letras de Ribeirāo Preto-USP, ex-psicóloga colaboradora do Hospital-Dia da Faculdade de Medicina de Ribeirão Preto-USP. Endereço para correspondência: Av. Bandeirantes, 3900 - 14040-901 - Ribeirão Preto - SP. E-mail: lenisemotta@uol.com.br

'Artigo recebido para publicação em março de 2002; aceito em julho de 2002.
}

usuários a possibilidade de tratamento intensivo, sem ênfase no leito, incluindo a família, visualizando o hospital como o local onde o processo terapêutico tem apenas início (Blaya, 1960; Campos, 1986; Zusman, 1992).

Contel, Benzato e Oda (1995) descrevem a hospitalização parcial como uma concepção de tratamento com larga abrangência, ultrapassando o âmbito particular da saúde mental. Em linhas gerais, a noção de hospitalização parcial indica ao menos as seguintes expectativas: a) opção por tratamento menos restritivo; b) ausência de exclusão comunitária; 


\section{Lenise Freitas Motta}

c) ênfase na participação grupal; e d) interdisciplinaridade como eixo do trabalho.

A definição da clientela e dos programas terapêuticos incluídos no projeto assistencial de um HD é determinada pelo tipo de sistema de saúde do qual ele é parte, bem como pelas relações estabelecidas com os demais serviços em termos de fluxo de pacientes.

Segundo Contel et al. (1995), o HD não pode ser pensado senão como parte de um todo, de uma estrutura mais complexa e, por esse motivo, a avaliação de seus resultados deve levar em consideração a efetividade global do sistema de atenção a que ele está vinculado. Por outro lado, a concepção de HD não implica necessariamente compromisso com esta ou aquela técnica terapêutica. Via de regra, conjugam-se métodos psicoterápicos (individuais e, principalmente, grupais), psicofarmacológicos, abordagem familiar e atividades expressivas variadas. A escolha da técnica mais adequada depende, em última instância, da populaçãoalvo do serviço.

A organização e funcionamento do serviço baseiam-se, predominantemente, nos pressupostos da comunidade terapêutica e da psiquiatria dinâmica. Procura-se ver a pessoa com distúrbio mental como um ser incluído dentro de um grupo - o familiar, que por sua vez está inserido em um contexto maior, macrossocial, ou seja, enfoca-se o paciente em seus aspectos bio-psico-social.

O serviço tem critérios amplos de aceitação em relação ao diagnóstico psiquiátrico; em geral, são pacientes provenientes de internação integral para continuidade do tratamento e/ou readaptação social, neuróticos graves, deprimidos, psicóticos e com reações de ajustamento. Evita-se a inclusão de pacientes com transtornos de personalidade, transtornos mentais orgânicos, mentais e de comportamento decorrentes do uso de substâncias psicoativas e retardo mental. O tempo de semiinternação é variável e decorrente das condições clínicas dos usuários, sendo em geral, em torno de dois meses (Campos, 1986).

Hoge e McLoughlin (1991) relatam que a psicoterapia de grupo em Hospital-Dia tem sido considerada pelos pacientes como uma das principais modalidades de tratamento. Os autores apontam para algumas dificuldades de condução dos grupos por haver um número limitado de sessões, mudanças constantes nos participantes e a variedade de diagnósticos e sintomatologia.

Para Bellack, Turner, Hersen e Luber (1984), o tratamento grupal em Hospital-Dia deve se basear. em pressupostos do modelo de aprendizagem social, sendo que o grupo necessita ser altamente estruturado, com foco educativo, visando o aprendizado de habilidades sociais e a ressocialização do paciente.

Segundo Feijoó (1993), as atividades em Hospital-Dia propõem uma adaptação ativa à realidade e a ressocialização. A psicoterapia de grupo favorece a melhora clínica através da criação de vínculos entre os pacientes, além de permitir ampla discussão de temas e de fornecer suporte emocional.

Contel (1991) menciona que o trabalho com grupos em HD configura um riquíssimo processo de ensino, aprendizagem e de crescimento humano. Foi a partir dessa linha de pensamento que a psicoterapia de grupo ou a grupoterapia começou a ter destaque no $\mathrm{HD}$, atuando como um espaço redimensionado de tratamento ao doente mental.

$O$ presente trabalho enfoca uma modalidade específica de intervenção em grupo ainda pouco difundida, a Psicoterapia de Grupo com Casais (PGC). No serviço em questão, um Hospital-Dia público ligado à Universidade, esse tipo de grupo terapêutico foi implantado em 1997, com o objetivo de destacar o casal como pólo de intervenção no tratamento, assim como apoiá-lo numa situação de crise, já que um dos cônjuges encontra-se em regime de semi-internação na referida instituição.

\section{Objetivo}

O presente trabalho tem como objetivo descrever esta modalidade de tratamento, a Grupoterapia com Casais no contexto de um HospitalDia, a partir do registro de onze sessões psicoterápicas consecutivas.

\section{Método}

\section{A Grupoterapia com Casais no Hospital-Dia}

Segundo Contel et al. (1995), a concepção de HD não implica necessariamente compromisso com esta ou aquela técnica terapêutica. Conjugam-se 
métodos psicoterápicos (principalmente grupais), psicofarmacológicos, abordagem familiar e atividades expressivas variadas, entre outros recursos de intervenção.

O contexto institucional em que se insere a presente investigação (HD) dispõe atualmente de 16 vagas a usuários maiores de 15 anos, em regime de semi-internação psiquiátrica. O atendimento é oferecido de segunda à sexta-feira, das 7:30 às 16 horas.

De acordo com Contel et al. (1997), a grupoterapia com casais foi introduzida nesse serviço considerando-se que de $40 \%$ a $60 \%$ dos pacientes em tratamento são casados ou vivem em união permanente.

A PGC corresponde a um grupo terapêutico de apoio e se caracteriza por ser aberto, pois há possibilidade de inclusão de novos pacientes admitidos no hospital-dia; homogêneo, porque todos os pacientes são casados ou vivem em união permanente - sendo assim, um dos cônjuges encontra-se em tratamento no hospital e o outro compartilha a situação de conviver com um cônjuge portador de grave transtorno mental; ede tempo limitado, porque quando o paciente recebe alta o casal é desligado do grupo.

A instalação desse grupo de apoio provém da necessidade de se trabalhar o núcleo familiar formado pelo "casal", pois observou-se, de forma empírica, que o cônjuge do paciente exercia significativa influência sobre o tratamento, ou ainda, devido à necessidade de destacar o casal como pólo de intervenção no tratamento.

Trata-se de uma psicoterapia de tempo definido e objetivos limitados, que visa apoiar o casal que vive uma situação de crise, desencadeada em grande parte pela presença do tranștorno mental de um dos cônjuges. Portanto, não se objetiva com o tratamento focalizar a relação conjugal de per si. O objetivo é criar um contexto de aprendizagem grupal para obter mudanças de comportamento, a partir de uma ampliação das possibilidades de compreensão da doença e do tratamento.

Dessa forma, a PGC é realizada semanalmente, com duração de 1:30 horas, sob a coordenação de um médico-psiquiatra e uma terapeuta ocupacional, em esquema de co-terapia. $\hat{E}$ obrigatória a presença de ambos os cônjuges, sendo solicitado que todos compareçam no horário e que permaneçam até o fim da sessão.

É importante notar que o limite de duração do processo terapêutico é fixado desde o início, coincidindo com o período de semi-internação do cônjuge acometido pelo transtorno mental. Um estudo anterior mostrou que o índice de adesão dos casais tem sido de $90 \%$, e que cada casal freqüenta, em média, de 4 a 8 sessões (Contel, 1997).

Os pacientes e seus cônjuges costumam sentar-se em círculo, em uma mesma sala, especialmente projetada para a realização de grupos na instituição.

O terapeuta explicita os objetivos do grupo no início de cada sessão, mas ao contrário dos outros grupos oferecidos no contexto do $\mathrm{HD}$, não há agendamento prévio dos assuntos. A participação de todos os membros é estimulada, sugerindo-lhes que tragam assuntos do seu interesse para serem examinados.

O trabalho terapêutico é mantido no plano consciente e real da interação grupal, evitando-se o uso de interpretações. Abordam-se os conteúdos emergentes, na busca de um insight intelectual e emocional que favoreça a melhora sintomática.

Devido à presença de um ou mais casais, privilegia-se no grupo temas do "aqui e agora" das interações de cada casal em particular e do conjunto dos casais, com o objetivo exclusivo de melhorar o funcionamento conjugai de cada um dos pares. Os assuntos podem ficar focalizados inicialmente em apenas um casal, mas tanto o coordenador como a co-terapeuta estimulam a interação de todos os casais.

As falas dos participantes não são interpretadas, mas apresentadas ao grupo para que juntos (coordenadores e casais) emitam opiniões que reflitam a compreensão de cada participante, buscando-se uma integração. Este acordo pode ser de ordem operacional (por exemplo, prescrição de tarefas a serem executadas como "lição de casa"), ou de ordem comunicacional (por exemplo, algum "mal-entendido" na comunicação do casal que mereça esclarecimentos) ou ainda de ordem emocional (mágoas, ressentimentos e outros sentimentos que emergem entre os membros do casal e que são 


\section{Lenise Freitas Motta}

compartilhadas com o grupo).

Ao final de cada grupo o coordenador solicita a cada participante que diga o que vai levar daquela sessão, ou seja, há uma avaliação individual dos participantes a respeito de suas vivências do processo grupal naquele dia.

\section{Participantes}

Participaram deste estudo oito pacientes de ambos os sexos, semi-internados no $\mathrm{HD}$, e seus respectivos cônjuges, que freqüentaram o serviço no período compreendido pela investigação (onze semanas consecutivas).

\section{1-Critérios de inclusão no estudo:}

a) Do ponto de vista dos pacientes:

- Estar em regime de semi-internação na instituição citada;

- Estar vivendo em união permanente (casados/ as e ou amasiados/as) com seus parceiros no momento da admissão no HD.

b) Do ponto de vista do paciente e seu cônjuge:

- Aceitar, voluntariamente, participar do estudo e permitir a gravação das sessões grupais, bem como a utilização dos dados obtidos em publicações científicas, sendo garantido o direito ao anonimato e à preservação do caráter confidencial e sigiloso das informações.

\section{2-Caracterização dos participantes:}

A Tabela 1 apresenta a descrição dos participantes da PGC segundo suas características sociodemográficas e clínicas (diagnóstico descritivo, de acordo com a CID-10).

Tabela 1: Caracterização dos participantes da PGC em função do gênero, idade, nível de escolaridade, tempo de união conjugal, número de filhos e categoria diagnóstica (CID-10) em que se enquadra o cônjuge acometido.

\begin{tabular}{l|l|c|l|c|c|c}
\hline $\begin{array}{c}\text { Partici- } \\
\text { pantes }\end{array}$ & Sexo & $\begin{array}{c}\text { Idade } \\
\text { (anos) }\end{array}$ & Escolaridade & $\begin{array}{c}\text { Tempo de } \\
\text { união (anos) }\end{array}$ & $\begin{array}{c}\text { Número } \\
\text { de filhos }\end{array}$ & (CID-10)** \\
\hline $\mathrm{C} 1 \mathrm{~m}^{*}$ & FEM & 62 & ensino médio completo & 38 & 3 & F33.3 \\
\hline $\mathrm{C} 1 \mathrm{~h}$ & MASC & 63 & ensino médio completo & 38 & 3 & - \\
\hline $\mathrm{C} 2 \mathrm{~m}$ & FEM & 48 & ensino médio completo & 25 & 4 & - \\
\hline $\mathrm{C} 2 \mathrm{~h}^{*}$ & MASC & 51 & ensino supcrior incompleto & 25 & 4 & F33.2 \\
\hline $\mathrm{C} 3 \mathrm{~m}^{*}$ & FEM & 29 & ensino básico incompleto & 7 & 1 & F20.5 \\
\hline $\mathrm{C} 3 \mathrm{~h}$ & MASC & 30 & ensino básico incompleto & 7 & 1 & - \\
\hline $\mathrm{C} 4 \mathrm{~m}$ & FEM & 53 & ensino básico incompleto & 31 & 3 & - \\
\hline $\mathrm{C} 4 \mathrm{~h}^{*}$ & MASC & 53 & ensino básico incompleto & 31 & 3 & F43.20 \\
\hline $\mathrm{C} 5 \mathrm{~m}^{*}$ & FEM & 43 & ensino médio completo & 10 & 2 & F31.0 \\
\hline $\mathrm{C} 5 \mathrm{~h}$ & MASC & 52 & ensino superior completo & 10 & 2 & - \\
\hline $\mathrm{C} 6 \mathrm{~m}^{*}$ & FEM & 28 & ensino básico incompleto & 12 & 2 & F32.1 \\
\hline $\mathrm{C} 6 \mathrm{~h}$ & MASC & 36 & ensino médio incompleto & 12 & 2 & - \\
\hline $\mathrm{C} 7 \mathrm{M}^{*}$ & fem & 42 & ensino básico incompleto & 25 & 2 & F45.4 \\
\hline $\mathrm{C} 7 \mathrm{H}$ & masc & 44 & ensino básico completo & 25 & 2 & - \\
\hline $\mathrm{C} 8 \mathrm{M}^{*}$ & fem & 42 & ensino básico completo & 25 & 3 & F20.0 \\
\hline $\mathrm{C} 8 \mathrm{H}^{*}$ & masc & 44 & ensino básico completo & 25 & 3 & - \\
\hline
\end{tabular}

=paciente. $\mathrm{C}=$ casal; $\mathrm{m}=$ mulher; $\mathrm{h}=$ homem.

$*_{* *}^{*}=$ F33.3=Transtorno depressivo recorrente, episódio atual grave com sintomas psicóticos; F33.2=Transtor depressivo recorrente, episódio atual grave sem sintomas psicóticos; F20.5=Esquizotrenia residual; F43.20=Transtor de ajustamento (Reação depressiva breve); F31.0=Transtorno afetivo bipolar, episódio atual hipomaníar F32.1=Transtorno depressivo moderado; F45.4=Transtorno doloroso somatoforme persistente; F20.0=Esquizofres paranóide.

Os dados sistematizados na Tabela 1 mostram que os participantes da PGC apresentam um perfil extremamente diversificado, tanto do ponto de vista sociodemográfico como clínico. A amplitude da faixa etária varia de 28 a 63 anos e o grau de escolaridade transita do nível básico incompleto ao superior 
completo. O nível de instrução entre os cônjuges é equivalente em cinco casais. Nos três casais restantes, a escolaridade do cônjuge masculino é maior. Dentre os participantes acometidos pelo transtomo mental, quatro apresentam o mesmo nível de escolaridade do cônjuge, dois apresentam nível inferior e os outros dois, nível superior em relação ao cônjuge "sadio". O tempo de coabitação varia de 7 a 38 anos e o número de filhos, de 1 a 4 . Os cônjuges portadores de transtorno mental se subdividem em cinco mulheres e três homens. Os diagnósticos psiquiátricos também se apresentam diversificados, abrangendo desde transtornos depressivos à esquizofrenia.

\section{3-Número de sessões:}

Segundo Minayo (1993), o recorte ideal, quando se utiliza o referencial qualitativo, é aquele "que possibilita abranger a totalidade do problema estudado em suas múltiplas dimensões". O fato de ter utilizado 11 sessões para análise nesse estudo foi devido à tentativa de apreender a rotina institucional, bem como a perspectiva de acompanhar o fluxo e a rotatividade dos usuários, que implicava em entrada e saída de novos participantes no grupo. Considerando-se que os pacientes permanecem em tratamento por um período médio de quatro a oito sessões, o recorte temporal escolhido permitiu estabelecer um corpus que abrangeu o processo terapêutico integral de quatro casais. Três casais prosseguiram em tratamento e um abandonou o serviço.

\section{4-Frequiência dos participantes:}

A Tabela 2 sistematiza os dados referentes à freqüência de participação dos casais às sessões.

Os dados indicam que, considerando-se as 11 sessões registradas, quatro casais apresentaram um índice de comparecimento a todas as sessões durante o período de semi-internação; os demais casais tiveram um índice de aderência entre $50 \mathrm{e}$ $80 \%$. O número máximo de casais por sessão foi quatro e o mínimo, um.

Tabela 2: Freqüência dos casais às sessões da PGC no período abrangido pelo estudo.

\begin{tabular}{|c|c|c|c|c|c|c|c|c|c|c|c|c|}
\hline & $\mathrm{S1}$ & $\mathbf{S 2}$ & S3 & 54 & $\mathrm{S5}$ & 56 & $S 7$ & S8 & S9 & S10 & S11 & $\%$ \\
\hline $\mathrm{Cl}$ & $x$ & $\bar{F}$ & $\mathrm{X}$ & $x$ & $\mathrm{X}$ & $\mathrm{F}$ & $F$ & $\mathrm{X}$ & $\mathrm{X}$ & $\mathrm{X}$ & $\overline{A B}$ & 70 \\
\hline $\mathrm{C2}$ & $\mathrm{X}$ & $\mathrm{F}$ & F & $\bar{x}$ & $\mathrm{X}$ & $\overline{A L}$ & $\mathrm{AL}$ & $\mathrm{AL}$ & AL & AL & $\mathrm{AL}$ & 60 \\
\hline $\mathrm{C3}$ & $\mathrm{X}$ & $F$ & $\bar{F}$ & $\bar{x}$ & $\overline{\mathrm{AL}}$ & $\mathrm{AL}$ & $\overline{\mathrm{AL}}$ & $\overline{\mathrm{AL}}$ & $\mathrm{AL}$ & $\overline{\mathrm{AL}}$ & $\mathrm{AL}$ & 50 \\
\hline C4 & NA & $X$ & $\mathrm{X}$ & $X$ & $X$ & $\mathrm{AL}$ & $\mathrm{AL}$ & $\mathrm{AL}$ & $\overline{A L}$ & $\mathrm{AL}$ & $\mathrm{AL}$ & 100 \\
\hline$\overline{C 5}$ & $\mathrm{NA}$ & NA & $\mathrm{NA}$ & $\mathrm{NA}$ & $\mathrm{X}$ & $\mathrm{X}$ & $\mathrm{X}$ & $\mathrm{X}$ & $\mathrm{X}$ & $\mathrm{X}$ & $\mathrm{AL}$ & 100 \\
\hline C6 & NA. & $\mathrm{NA}$ & NA & $\widehat{N A}$ & $\overline{\mathrm{NA}}$ & NA & $X$ & $x$ & $\mathrm{X}$ & $\mathrm{X}$ & $\mathrm{F}$ & 80 \\
\hline$\overline{C 7}$ & NA & $\mathrm{NA}$ & $\mathrm{NA}$ & $\mathrm{NA}$ & NA & $\overline{\mathrm{NA}}$ & $\overline{N A}$ & NA & $\mathrm{X}$ & $\mathrm{X}$ & $\mathrm{X}$ & 100 \\
\hline $\mathrm{C8}$ & $\mathrm{NA}$ & $\mathrm{NA}$ & $\mathrm{NA}$ & NA & $\mathrm{NA}$ & $\mathrm{NA}$ & $\mathrm{NA}$ & $\mathrm{NA}$ & $\mathrm{NA}$ & $\mathrm{NA}$ & $\mathrm{X}$ & 100 \\
\hline TOTAL & 3 & 1 & 2 & 4 & 4 & 1 & 2 & 3 & 4 & 4 & 2 & \\
\hline
\end{tabular}

\section{Procedimento-}

O projeto de pesquisa foi submetido e aprovado ${ }^{1}$ pelo Comitê de Ética em Pesquisa da Faculdade de Medicina de Ribeirão Preto-USP. E procurou-se garantir o compromisso ético de sigilo e respeito em relação aos participantes, que foram previamente esclarecidos sobre a natureza e objetivos do estudo e formalizaram seu consentimento por escrito, mediante assinatura de um Termo de Consentimento Livre e Esclarecido. Essa abordagem foi feita com cada casal, assegurando-lhes que se

\footnotetext{
'A pesquisa com seres humanos deve seguir as diretrizes $\mathrm{e}$ normas definidas a partir de 1997 , no Brasil.
}

não concordassem em participar não haveria prejuízo em relação ao atendimento institucional.

Como se tratava de um grupo aberto, havia uma nova explicitação da pesquisa no início de cada sessão, a cargo do coordenador, quando era reafirmada a questão da garantia do sigilo por parte do coordenador, do co-terapeuta e dos observadores em relação ao que ocorria no grupo, bem como o uso exclusivo do material obtido para fins de estudo, não havendo identificação dos participantes.

\section{Coleta de dados/registro das sessões}

11 sessões psicoterápicas, realizadas na base 


\section{Lenise Freitas Motta}

de uma por semana, foram gravadas em vídeo e, posteriormente, transcritas na íntegra e de forma literal. A opção pela gravação em vídeo justifica-se pela possibilidade de se obter maior acuidade quando se pretende captar verbalizações de certo número de sujeitos, que podem inclusive ser expressas simultaneamente.

\section{Análise dos dados}

Os dados foram submetidos à modalidade de análise de conteúdo denominada categorial temática (Triviños, 1987; Minayo, 1993).

De acordo com Minayo (1995), a análise temática pressupõe a descoberta de núcleos de sentido que compõem uma comunicação, cuja presença ou freqüência configurem um significado para o fenômeno visado, denotando valores de referência e características do discurso a partir das unidades de significação ou de registro. Estas correspondem ao segmento de conteúdo a se considerar unidade base, visando a categorização. foram:

As etapas seguidas para esse procedimento

Pré-análise: Organização dos dados através da leitura flutuante e exaustiva das transcrições das sessões, compreendendo a sistematização geral das idéias, através da elaboração de unidades de significação.

Exploração do material: Com os dados já categorizados, a busca de sínteses convergentes e divergentes de idéias, ou na expressão de concepções que não fossem comprometidas com alguma teoria em particular (Triviños, 1987).

Interpretação dos dados: depois das sínteses, houve o destaque por categorias, dando significado aos principais achados.

Para melhor compreensão e organização procurou-se descrever o grupo a partir de dois vértices diferentes: terapeutas (Coordenador, $\mathrm{Co}$; $\mathrm{Co}$ terapeuta, $\mathrm{Ct}$ ) e casais participantes.

\section{Resultados e Discussão}

\section{Descriçãa da Psicoterapia de Grupo com Casais}

O vértice dos terapeutas:

a) Formas de condução do grupo a1) Diretividade:

Uma das características principais da PCG é o papel central que os terapeutas assumem na condução do grupo, apresentando uma atitude predominantemente diretiva, isto é, havendo intervenção ativa na condução, fornecendo apoio, orientação e esclarecimento quando necessário, usando da transparência, destacando a universalidade e instilando esperança.

Outro aspecto que denota o papel central dos terapeutas é o fato de que predominam as interações com eles, mais do que as trocas dos casais entre si. Esta dinâmica está relacionada à forma diretiva com que o grupo é conduzido, sendo os terapeutas o foco principal de aterição. Eles são solicitados o tempo todo a responderem perguntas, darem orientações, esclarecimentos, bem como modelos e padrões de conduta. Os homens tendem a se dirigir mais ao terapeuta masculino, enquanto que as mulheres solicitam mais a atenção do feminino.

a2) Orientações aos participantes

Uma das principais formas de intervenção dos terapeutas no grupo é o fornecimento maciço de orientações, um recurso utilizado, sobretudo, nos grupos dirigidos ao apoio (Fiorini, 1984).

Co-Sabe o que eu faria se fosse você?

C3h- Me dá uma orientação.

Co- Quem faz a comida pra você levar pro trabalho?

C3h-Ela faz, a C3m*, ela arruma.

Co-Então eu pegaria só isso, só isso: ter a sua comida feita por ela. Se ela conseguir fazer a sua comida todo dia e você se relacionar com ela através dessa comida, pode ser que isso ajude ela a se manter saudável.

\section{a3) Esclarecimento/informações}

São intervenções que visam proporcionar a disseminação de conhecimentos atualizados sobre a doença, mediante uma linguagem compatível e adaptada ao nível sócio-cultural do familiar. $\mathrm{O}$ terapeuta tenta nomear as dúvidas dos participantes e, a partir do conhecimento sobre a enfermidade e o tratamento, amenizar o sofrimento frente ao desconhecido, auxiliando no manejo do paciente. 
Clm*. Doutor, qual a diferença entre depressão e esquizofrenia? Minha médica antes me disse que eu tenho esquizofrenia. Co- $E$ uma oportunidade que a senhora tá tendo aqui no Hospital-Dia de ver o que é uma depressão e o que é uma esquizofrenia. Por exemplo, uma pessoa que faz uma pergunta como a senhora faz, em geral não é esquizofrênica, entendeu? Porque o seu raciocínio tá funcionando: "Será que eu sou esquizofrênica? Será que eu tenho depressão?" O seu pensamento tá funcionando, a senhora tá questionando, tá curiosa, e na esquizofrenia é comum a pessoa ter alucinações, como a alucinação auditiva, que é a pessoa ouvir vozes, vozes que só tem na cabeça dela. Na esquizofrenia é comum a pessoa ter delírio, se sente perseguido, tem muita desconfiança, ela acha que o vizinho tá falando dela. E outra coisa é que a esquizofrenia costuma ser uma doença do adolescente para o adulto jovem, e não em uma pessoa da sua idade.

a4) Intervenções explorativas

São as intervenções que buscam investigar o que o cônjuge não acometido conhece a respeito do transtorno mental e de seu tratamento, em que o participante é incentivado a falar livremente sobre suas idéias e sentimentos (Fiorini, 1984), ficando-se atento à maneira como cada um consegue subjetivar suas questões.

\footnotetext{
Ct- Então a noite ele passava mal? C4m- A noite...

C4h*. Mas durante bastante tempo eu sentia muito irritado, muito nervoso. Co-Antes de começar a se sentir assim? $C 4 h^{*} E$, antes desse dia que eu arrumei, fui lá na consulta, falei pra $C 4 m$, eu tô tão nervoso. Eu não sei porquê. Será o que tá acontecendo comigo?

Co- Não é do seu gênero ser nervoso?

$C 4 h{ }^{*}-N a \tilde{o}$, não é, não é.

Co-O que que aconteceu, né, pra ficar ruim assim, grave de uma hora para outra?
}

\author{
C4m-Será que era da cerveja que ele \\ tomou? \\ Co- Uma cerveja que ele tomou? \\ $C 4 m-E$. \\ Co- $A$ senhora acha que pode ser? \\ C4m-Uai, sei lá. Tem hora que eu penso \\ que é, porque ele tomou remédio pra \\ pressão.
}

b) Estratégias utilizadas para a intervenção:

b1) Estímulo à interação entre os casais

Em função do modo peculiar como se dá a estruturação do grupo e sua condução diretiva, os terapeutas buscam estimular a interação entre os casais, solicitando-os para que emitam suas opiniões a respeito dos assuntos discutidos.

Ct- $O$ que eu tô entendendo a respeito da sobrecarga que o senhor falou é que a dona $\mathrm{Clm}^{*}$ deixou de fazer as coisas e foi deixando as outras pessoas fazerem por ela. Co-Vamos ver se aconteceu a mesma coisa com o seu $C 4 h^{*}$, de deixar de fazer as coisas por ele mesmo, porque o que nós pensamos é que a dona Clm* está aqui por isso: perdeu muito dessa capacidade que o senhor gostaria que ela voltasse a ter. O senhor quer contar um pouco para a dona $C 1 m^{*}$ como foi com o senhor, seu C4h*?

b2) Procura de novos modelos de relacionamento

A discussão com frequiência gira em torno da busca de outros modelos de relacionamento, mais adaptativos, a partir do depoimento dos diversos casais. $\mathrm{O}$ incentivo é para que encontrem padrões menos regredidos de comportamento. A abordagem grupal favorece essa transformação, uma vez que propõe tratar o indivíduo em situação, em vez de isolá-lo de seu contexto.

Ct-Sabe, eu tô pensando que novamente volta pra coisa do equilíbrio, né, porque a gente tá falando dos opostos: a dona CIm* não se preocupa com o negócio das contas e a C6m* se preocupa demais. A gente viu que não dá, tem que ter um equilíbrio, $e$ 
nas tarefas de casa também. Então não é oito, nem oitenta.

b3) Discussão ao nível do concreto

A condução da discussão grupal é feita, muitas vezes, através da tentativa de pormenorizar, no nível do concreto, as situações rotineiras trazidas pelos casais, com o intuito de que, na sequiência lógica dos fatos, possa ser encontrado o foco de dificuldade. Com esta técnica, o objetivo é encontrar o ponto de conflito, clarificando e/ou renomeando-o, visando proporcionar alívio psicologico da ansiedade gerada pelo problema examinado.

C8m*- Eu fui no supermercado.

Ct- Você foi sozinha?

C8m*. Fui com a minha sogra, mas eu empurrei o carrinho.

Ct-Mas quem escolheu as coisas na prateleira?

C8m*-Eu! Eu fui com uma lista.

Ct-Você escolheu os produtos?

C8m*-Sim, e na hora de pagar eu levei um cheque assinado e paguei. Só que eu não gostei muito porque tinha um rádio que me atrapalhou

Ct-Fora isso, você conseguiu fazer as compras sozinha. Isso é muito importante, né, fazer as coisas com as pessoas por perto dando um apoio.

Ct-Vocês estão falando sobre o equilibrio, e uma questão é como a gente percebe as coisas, né. Então a gente pode perceber assim: "meu marido deveria ter pego o talão de cheque, deveria ter ido na prefeitura, deveria ter feito tal coisa até as 4 horas da tarde, não fez isso, e não vai dar conta de fazer, então eu acho que ele é irresponsável no serviço dele, ele é irresponsável como pai, ele é irresponsável em todas as coisas e alguém tem que estar cobrando porque ele é irresponsável em todas as coisas e eu fico tão preocupada com as responsabilidades dele que eu acabo esquecendo das minhas responsabilidades." b4) Destaque da universalidade

Os terapeutas tentam destacar a universalidade dos problemas trazidos pelos participantes no processo da interação grupal. Com isso, os integrantes do grupo podem perceber que não estão sozinhos com seus problemas (Vinogradov \& Yalom, 1992).

$C 1 m^{*}$ É os remédio que tá muito forte, eu não tô conseguindo dar conta.

Ct-Os remédios são fortes ou as pessoas que exigem muito da senhora?

$C 1 m^{*}$ - Pode ser.

C6m*- Eu sinto a mesma coisa que a dona Clm*, parece que as minhas pernas trava tudo.

Clm*. Chega até a formigar.

Co- Eu acho que esse é um assunto muito comum de casal: "quem dá mais?" A cobrança é muito grande, né, um acha que dá muito e o outro não responde, né, e às vezes nenhum dos dois consegue dar, um espera tanto e não percebe que o outro não consegue. Isso é muito comum. desde o café da manhä, no almoço, na hora de deitar, às vezes um puxa o lençol pra um lado, descobre o pé do outro, o outro já fica bravo. Isso é muito de casal, por isso é que essa reunião tem características próprias.

Assim, os esforços do coordenador em apontar para o grupo que todos estão passando por situações de sofrimento semelhantes (universalidade) atuam como elemento aglutinador, ou seja, transformam aspectos negativos em oportunidade de apoio mútuo.

b5) Uso da transparência

O terapeuta utiliza ainda da transparência, ou seja, relata suas próprias reações, com franqueza e honestidade, para esclarecer expectativas e reações irrealistas no grupo (Vinogradov \& Yalom, 1992).

Co- (...) è também fumava dois maços de cigarro por dia, peguei uma pneumonia, precisei ser internado durante uma semana. 
Quando eu tive alta, parei de fumar. Eu acho que foi uma conversão... O que me ajudou a me converter foi o medo de morrer.

Em outro momento o grupo discutia sobre as dificuldades em lidar com filhos adolescentes $e$ os participantes cogitam se haveria uma determinada idade em que seria mais fácil educar os filhos.

Ct- $A$ idade boa é de 7 a 10 anos. É boa, não é?

Co- É a época do pai herói, né. Dos 7 aos 10 eu ensinei meus filhos a pescar, eu era o máximo, eu sabia pôr minhoca no anzol, eu sabia botar a linha, eu sabia onde eu ia jogar para pegar o peixe, ai eles pegavam o peixe. Depois dos 11, oh!!

b6) Discriminação das queixas do casal

Os terapeutas abordam questões relativas aos papéis peculiares de esposa e/ou esposo desempenhados no casamento, tentando fazê-los reconhecer que algumas questões são próprias deles e não decorrentes do distúrbio mental apresentado por um dos cônjuges.

C3h-Eu falo assim, vamos supor, tipo assim, vai passar uma roupa, então passa bem passado, né!

Co-Você acha que a $C 3 m^{*}$ consegue passar bem sua roupa?

C3h-Ela passava, né, agora é que fica difícil.

C3m*- Enjoado!

Co- $O$ que você falou; $C 3 m *$ ?

C3m*- Que ele é enjoado, gosta das coisa tudo certinho.

Co- Então o que vocês tem são diferenças: ela acha que você é enjoado, você se acha enjoado?

C3h- Ah, eu me acho!

\section{Q vértice dos casais participantes}

a) Passividade
Observou-se que os participantes do grupo tendem a assumir uma postura mais "passiva", ou seja, na maioria das vezes colocam suas percepções e sentimentos apenas quando solicitados pelos terapeutas. Todavia, observou-se que a postura era muitas vezes silenciosa, mas demonstrava atenção ou interesse pela tarefa.

O que supõe é que, devido ao momento de profundo sofrimento por que estão passando, os casais requeiram um ambiente terapêutico com maior estruturação e acolhimento por parte dos terapeutas, o que pode justificar a dificuldade de interação observada.

b) Queixas

Dentre as principais temáticas trazidas pelos participantes, destacam-se as queixas dos cônjuges não acometidos em relação aos pacientes; parece haver dificuldade em perceber os problemas no contexto relacional do casal, com a tendência em atribuir os problemas unicamente ao parceiro(a).

As queixas foram subdivididas em:

b1) O comportamento inadequado do paciente Os cônjuges não acometidos utilizam o grupo como espaço para ventilar queixas em relação ao comportamento dos pacientes, falando de sua inadequação e indayando da possibilidade de ser atribuível à doença mental ou não.

C2m- Não vai virar nada, ele não faz nada. Co- Não faz nada?

Ct-Mas o que ele poderia estar fazendo? C2m-Não sei, ele tem que se ocupar... Coisas pra fazer tem, voltar a dirigir já é uma boa opção... Agora, a gente não sabe se pode forçar, se ele vai ter condições... é um saco!

Os cônjuges buscam orientações e informações sobre a melhor forma de agir diante das condutas desajustadas do(a) parceiro(a).

C6h-Se você näo tivesse ficado enfezada como você ficou, e sair, você tinha escutado.

Co-Por um outro lado, nós achamos que é 
78 Lenise Freitas Motta

da doença, e esse estado nós também achamos que é muito sofrido, muito doloroso.

C6h-Ela aumenta demais as coisas.

Co- Uma coisinha assim, fica assim (faz gesto de pequeno para grande) por causa da doença.

b2) Os pacientes deixam de cumprir seus deveres de esposo/esposa e pai/mãe

Outra queixa trazida com bastante freqüência refere-se ao fato de o paciente deixar de executar seus papéis sociais, principalmente os relativos aos de esposo/esposa e pai/mãe.

C7m- (...) Olha, nem tirar o lixo pra fora pra mim ele faz. Outro dia eu tava muito atarefada, pedi pra ele buscar as criança na escola, que nada!

C7h*. Foi o dia da dor nas minhas costas. semana

b3) A piora dos pacientes durante o final de

Outra queixa trazida é a de que os pacientes, ao se distanciarem do ambiente protegido do HospitalDia, principalmente nos finais de semana, tendem a piorar em relação à sintomatologia apresentada.

C5h-O problema nosso é o final de semana. Chegava no Sábado descambava tudo, daí eu trouxe o problema aqui e eu tava com medo é por ser prolongado o feriado...

c) As dificuldades de relacionamento conjugal atribuídas ao parceiro

O cônjuge tem a percepção de que as dificuldades de relacionamento conjugal são causadas pelo(a) parceiro(a) e isto visto como a fonte do problema de saúde mental.

CIh-Sabe, né doutor, a gente sente falta de um agrado, de uma companheira. É duro porque a gente vai ficando muito sozinho, chega uma hora que você explode... espera, espera, e o outro ali, não reage... Cê fala vamo, acorda!
O paciente, ao mesmo tempo em que necessita do apoio do parceiro, percebe-o como origem de seus problemas.

C5m*. É assim... eu vou engolindo, engolindo e depois, quando eu explodo, é aquele estouro. Até eu tava muito preocupada com uma atitude que ele tomou há mais ou menos um mês atrás, mas continuei engolindo... Agora ontem eu cheguei quebrada daqui e ele me irritou. Procurei ajuda com o remédio, serviu, mas sei que isso não é o problema, o problema é ele.

C6m*- É igual eu, eu falo as coisas pra ele... Ele fala que não tá agüentando mais, que é ele que vai ficar doente, é isso que ele fala.

d) Execução de tarefas de acordo com as orientações oferecidas no grupo

A partir das orientações dos terapeutas, os casais tentam reproduzir, no contexto doméstico, o que aprenderam no grupo. Fica evidente, a partir de suas verbalizações, a necessidade do apoio do cônjuge (ou de outro membro da família) para colocar essas orientações em prática.

C5m*. Olha, eu tentei fazer como o Dr. X falou. Então eu preparei a lasanha no sábado, só pra pôr no forno no domingo, e eu cozinhei todos os legumes no sábado, deixei tudo prontinho, porque louça suja muito, e você precisa da ajuda de alguém pra lavar a louça. E eu tive essa ajuda. Ct-Então o que te ajudou foi você estar se organizando, e a presença do seu esposo pra te dar uma força.

C5m-Isso ajudou bastante.

\section{Conclusões}

Analisando-se os dados obtidos, pode-se afirmar que a modalidade de tratamento descrita (PCG) apresenta como principais características:

a) Do ponto de vista dos terapeutas 
Os terapeutas desempenham um papel central no grupo, conduzindo-o de forma a estimular ativamente a participação dos casais. A diretividade é uma característica saliente no manejo das sessões, embora haja ampla liberdade para que os casais tragam as questões que gostariam de trabalhar. A discussão dos assuntos muitas vezes é mantida ao nível do concreto, condizente com as características e necessidades da população atendida em um serviço público de saúde mental. A universalidade é um fator terapêutico bastante utilizado na abordagem dos problemas apresentados pelos casais, assim como também o oferecimento de informações. O estímulo à interação com os demais membros do grupo, a busca de novos modelos de relacionamento e o auxílio aos participantes no aprendizado, para discriminar aquilo que de seus problemas relacionais deve-se ou não à presença da doença mental, são estratégias de intervenção empregadas pela coordenação do grupo.

Outro recurso dos coordenadores para estimular a discussão é o uso da transparência, mediante o qual o terapeuta tenta permanecer o mais próximo possível do universo afetivo dos participantes, relatando suas próprias reações com franqueza e honestidade. Ao apresentar ao grupo fragmentos de sua experiência pessoal, o terapeuta visa encorajar os membros a se exporem com a mesma franqueza e sinceridade. Além disso, a transparência pode, segundo Vinogradov e Yalom (1992), auxiliar o grupo a corrigir expectativas irrealistas.

As táticas de intervenção utilizadas pelos terapeutas aproximam-se, em seus fundamentos técnicos, das estratégias descritas por Fiorini (1984) no contexto das psicoterapias de apoio (ou esclarecimento). Em intervenções que visam basicamente o apoio psicológico, como no caso do grupo formado por múltiplos casais no contexto da hospitalização parcial, o fornecimento aos participantes de orientações e informações a respeito do transtorno mental constitui uma importante ferramenta do arsenal terapêutico, paralelamente às intervenções que buscam investigar e valorizar o conhecimento que os próprios participantes trazem a respeito do transtorno mental e de seu tratamento.

O tipo de modelo de intervenção adotado também leva em conta que o grupo constituído pelos casais é bastante heterogêneo do ponto de vista do nível educacional, da faixa etária, do tempo de união dos casais e da problemática psiquiátrica que justifica a semi-hospitalização.

\section{b) Do ponto de vista dos participantes}

Os integrantes do grupo tendem a apresentar uma postura mais passiva, manifestando suas opiniộes apenas quando estimulados ou solicitados pelos coordenadores, sendo que os cônjuges não acometidos pelo transtorno mental utilizam o grupo para ventilar queixas em relação ao comportamento do paciente, falando das dificuldades vivenciadas no cotidiano familiar, quando eles deixam de realizar adequadamente seus papéis sociais e da sintomatologia agravada nos finais de semana.

Por outro lado, os cônjuges não acometidos também procuram utilizar o grupo como um espaço em que podem obter informações relativas à doença mental, sendo um dos principais pontos abordados 0 desejo de reconhecer nos problemas de comportamento de seu parceiro o que se deve ou não à doença. É possível que a apropriação desse conhecimento pelo familiar venha a favorecer um manejo mais adequado dos sintomas apresentados pelos pacientes. Na medida em que se incrementa a capacidade de discriminação do cônjuge sadio, aumenta-se o seu nível de tolerância para com os comportamentos inadequados do que está em sofrimento mental, levando a uma participaçăo mais efetiva e afetiva no tratamento. Assim, o parceiro pode se integrar como um elo importante dos cuidados terapêuticos e fúncionar como mediador entre o contexto familiar e a equipe de tratamento.

Tanto os pacientes como seus cônjuges parecem vislumbrar no grupo a oportunidade de aprenderem novos modelos de relacionamento e tentam pôr em prática, relatando seus êxitos e dificuldades nesse processo de mudança.

Essas características indicam que essa modalidade de tratamento, assim como as demais oferecidas no âmbito do HD (Contel, 1991), tem objetivos claramente definidos.

Baucom et al. (1998) acreditam que, provavelmente mais importante do que identificar problemas claros de relacionamento, seja existir uma clara formulação de como os padrões de interação entre o cônjuge e o paciente estão associados com o 


\section{Lenise Freitas Motta}

distúrbio (transtorno mental) em questão. Para Christensen (1999), a terapia de casais pode afetar positivamente a psicopatologia individual na medida em que reduz o relacionamento aflitivo.

$O$ foco da PGC é fixado na crise conjugal desencadeada pelo transtorno mental que acomete um dos cônjuges, sobretudo os prejuízos que afetam a organização da rotina doméstica e o cotidiano do casal. Assim, é em torno dessa dimensão focal que se deve procurar identificar os benefícios associados ao tratamento.

Procura-se envolver os cônjuges no tratamento com finalidade de: a) educá-los a respeito da natureza do transtorno mental; b) identificar e modificar as formas específicas de relacionamento inadequado que estão acentuadas no meio interpessoal dos pacientes, contribuindo para que os sintomas sejam mantidos; e c) estimular um contexto de relacionamento que encoraje o paciente a se comportar de forma que diminua a gravidade do distúrbio, ajudando-o a enfrentar as situações de forma mais eficaz, com maior sucesso (Baucom et al., 1998).

Nesse sentido, é possível afirmar que o modelo adotado é coerente com os pressupostos teóricos encontrados na literatura sobre tratamento grupal em $\mathrm{HD}$, que se baseiam no modelo de aprendizagem social (Bellack, Turner, Hersen \& Luber, 1984). Para tanto, o grupo necessita ser altamente estruturado, com foco psico-educativo, visando o aprendizado de habilidades sociais e a ressocialização do paciente, de modo a favorecer uma adaptação ativa à realidade (Feijoó, 1993).

A disfunção conjugal pode ser apresentada através de sintomas que os participantes submetem ao exame do grupo e este emerge como espaçocontinente para que as questões possam ser elaboradas, as relações de poder redimensionadas e o isolamento do casal diminuído. Encoraja-se a livre expressão de seus participantes, assim como são proporcionadas experiências de troca entre os casais que ativam mudanças positivas na área afetiva e cognitiva (Feld, 1997).

A ampla gama de experiências, tanto positivas quanto negativas, vivenciadas no coletivo grupal pelos casais, parece ter o condão de criar uma vasta rede de apoio, mediada pelo fornecimento de informações e orientações que ficam à disposição de cada participante e que poderão ser utilizadas no ambiente extraterapêutico, seja na tomada de decisões vitais, seja na adoção de novas estratégias para a melhora do relacionamento conjugal.

Dentro dessa perspectiva pode-se dizer que os pacientes, assim como seus cônjuges, enfatizam em suas falas durante as sessões de grupo o aprendizado proporcionado pela experiência compartilhada com os demais. Isto coincide com a observação de Watters (1982) de que o principal reforço do aprendizado é a seqüência de pequenos sucessos experimentados ao longo do caminho.

Nesse sentido, os participantes da PGC relatam com freqüência que aprenderam novas atitudes e comportamentos, na medida em que o grupo serviu de modelo. Pode-se, pois, afirmar que, dentro do referencial em que a PGC é praticada no HD, o contexto grupal favorece a modificação do comportamento através da observação direta dos modelos apresentados por outros cônjuges, auxiliado pelos sentimentos de universalidade potencializados pelo grupo e pela atitude ativa, firme e ao mesmo tempo transparente dos terapeutas, que parece ajudar na criação e manutenção de um clima grupal favorável a mudanças.

Parece verdadeiro que o fato de o paciente engajar-se em um tratamento com as exigências típicas de uma semi-internaçãa - que requer algum nível de comprometimento e co-responsabilidade da família-mobiliza maciçamente os recursos e forças curativas não apenas do paciente-identificado, como de toda a organização familiar, fazendo com que a PGC, tal como tem sido praticada, contribua para explicitar essa necessidade de co-responsabilidade do cônjuge, criando um dispositivo que propicia potencializar os recursos mobilizados na busca de uma melhor adaptação psicossocial.

Em síntese, na condução do grupo, os coordenadores buscam desenvolver em cada participante uma atitude de participação ativa no processo de tratamento, com os familiares sendo encorajados a buscar padrões menos regredidos de comportamento, podendo-se afirmar que traz benefícios essa abordagem grupal que se propõe a tratar o indivíduo em situação, em vez de isolá-lo de seu contexto. 


\section{Referências bibliográficas}

Baucom, D.H.; Shoham, V.; Mueser, K.T.; Daiuto, A.D.\& Stickle R. (1998). Empirically supported couple and family interventions for marital distress and adult mental health problems. American Psychological Association, p. 53-88.

Bellack, A.S.; Turner S.M.; Hersen, M.\& Luber, R. F. (1984). An examination of the efficacy of social skills training for chronic schizophrenic patients. Hospital and Community Psychiatry, 35, n. 10, p. 1023-1028.

Blaya, M. (1960). Conceitos e indicações do hospitaldia psiquiátrico. Revista da Associação Médica do Rio Grande do Sul, 4, n. 3, p. 64-68.

Brasil. Ministério da Saúde/SAS/CNS/PNDST-AIDS (1997). Diretrizes e normas regulamentadoras de pesquisas envolvendo seres humanos. Brasília.

Campos, M.A. (1986). O Hospital Dia como alternativa assistencial em psiquiatria. Tese de Doutorado, Faculdade de Medicina de Ribeirão Preto da Universidade de São Paulo, Ribeirão Preto-SP.

Christensen, A. (1999). Interventions for couples. Annual Review of Psychology, 50, p. 165-190.

Contel, J.O.B. (1991). Quinze anos de hospital dia psiquiátrico: contribuição ao estudo da prática de comunidade terapêutica, psicoterapia de grupo e princípios psicanalíticos em hospital psiquiátrico no Brasil. Jornal Brasileiro de Psiquiatria, 40, n. 4, p. 163-169.

Contel, J.O.B.; Benzato, C.M. \& Oda, A.R. (1995). Hospital Dia. In N.J. Botega (Org.), (p. 83/94) Serviços de saúde mental no hospital geral. Hucitec: São Paulo.

Contel, J.O.B.; Ferreira, R.D.M.D. \& Villas Boas, M.A. (1997). Grupo de Apoio para Casais durante tratamento de um dos cônjuges em Hospital Dia. In Contel, J.O.B. (Org.) VI Ciclo de Estudos em Saúde Mental da FMRP.USP, Ribeirão Preto: Gráfica São Francisco Editora.

Feijoó, A.H. (1993). Instituciones de internación psiquiátrica intermedia Hospital de Día-Hospital
- Hospital de Noche. Vertex, 4, n. 12, p. 104112.

Feld, B. (1997). An object relations perspective on couples group therapy. International Journal of Group Psychotherapy, 47, n. 3, p. 315-333.

Fiorini, H. (1984). Teoria e técnica de psicoterapias. Rio de Janeiro: Francisco Alves.

Hoge, M.A. \& McLoughlin, A. (1991). Group psychotherapy in acute treatment settings: theory and technique. Hospital and Community Psychiatry, 42, n. 2, p. 153-158.

Minayo, M.C.S. (1993). O desafio do conhecimento: pesquisa qualitativa em saúde. $3^{\mathrm{a}}$ ed. Rio de Janeiro: Hucitec/Abrasco.

Minayo, M.C.S. (1995). Pesquisa social: teoria, método e criatividade. Rio de Janeiro: Vozes.

Triviños, A.N.S. (1987). Introdução à pesquisa em ciências sociais: a pesquisa qualitativa em educação. São Paulo: Atlas.

Vinogradov, S. \& Yalom, I. (1992). Manual de psicoterapia de grupo. Porto Alegre: Artes Médicas.

Watters, W.W. (1982). Conjoint couple therapy. Canadian Journal of Psychiatry, 27, p. 91.

Zusman, I.A. (1992). Hospital Dia: uma perspectiva histórico-crítica. Jornal Brasileiro de Psiquiatria, 41, n. 8, 393-398.

Nota: O presente trabalho é parte da Dissertação de Mestrado defendida pela primeira autora em 2001, junto ao PPG em Psicologia da FFCL RP USP. Os autores desejam consignar um agradecimento especial à colaboração preciosa da equipe do Hospital-Dia da FMRP-USP durante a etapa de coleta dos dados, sobretudo o apoio e o encorajamento recebidos do Prof. Dr. José Onildo Betioli Contel. 